\title{
Constitutional Education: The Core of German Political Education
}

\author{
Wen Li, Yifan Ruan* \\ School of Marxism, China University of Geosciences, Wuhan, China \\ *Corresponding author
}

\begin{abstract}
The connotation of contemporary Germany political education involves all aspects of history, politics, economy, and society, but its core is education about constitutional knowledge and constitutional awareness. The concept of constitutional education runs through the history of Germany modern political education. "Constitutional patriotism" is the basic theory of contemporary Germany political education. In practice, people should establish the goal of political education on the basis of the constitution, carry out school political education on the basis of constitution, and select the social undertaker of political education on the basis of the constitution. Constitutional education is the core of Germany political education. Its essence is to obtain the public's approval of bourgeois rule and to maintain the capitalist constitutional system. The experience of German constitutional education has certain enlightenment significance to China's ideological and political education and constitutional education: we must attach great importance to constitutional education, strengthen the teaching of school constitutional education, and form a joint force of social constitutional education.
\end{abstract}

Keywords: Germany, Constitutional education, Political education, Constitutional patriotism

\section{宪法教育：德国政治教育的核心}

李文, 阮一帆*

中国地质大学（武汉），马克思主义学院，武汉，中国

“通讯作者

\section{中文摘要}

当代德国政治教育内涵涉及历史、政治、经济、社会诸方面，但其核心是有关宪法知识和宪法意识的 教育。宪法教育理念贯穿德国近现代政治教育历史，“宪法爱国主义”是当代德国政治教育的基础理 论。在实践中，以宪法为依据确立政治教育目标，以宪法为内容开展学校政治教育，以宪法为原则遴 选政治教育社会承担者。以宪法教育为核心的德国政治教育，其本质是获取民众对资产阶级统治的认 同，维护资本主义宪政体系。德国宪法教育的经验对我国思想政治教育以及宪法教育工作具有一定启 示意义: 要高度重视宪法教育, 加强学校宪法教育教学, 形成社会宪法教育合力。

关键词: 德国; 宪法教育; 政治教育; 宪法爱国主义

\section{1. 引言}

德国是西方近代以来最重视对民众实施政治教育 的国家之一。二战后, 德国统治集团以西方资产阶级核 心价值观为指引，构建其 “民主政治教育”

(Demokratischer Politischer Bildung) 体系, 在德 国社会极力传播西方资本主义政治文化, 以维护自身统
治。当代德国政治教育内涵涉及历史、政治、经济、社 会诸方面, 但其核心是有关宪法知识和宪法意识的教 育。这种以宪法教育为核心的政治教育, 使德国民众对 宪法所包含的内容体系、基本精神、价值取向有较高的 认可度，对德国统治集团及其资产阶级政府获取 “政治 合法性”起到关键性作用。 


\section{2. 宪法教育贯穿德国近现代政治教育历史}

早在 17 世纪, 德意志 “神圣罗马帝国” 就已有政 治教育的萌芽, 任务是为封建邦国培养政治、法律、军 队等方面的公职人员。自 18 世纪中叶以后, 德意志邦 国间就领土、政治、经济等领域展开激烈竞争，统治者 们为了动员国民、维护封建统治, 开始重视政治教育。 到 19 世纪末, 随德意志第二帝国的建立, 政治教育开 始得到系统化、专门化, 其目标是从根本上塑造德意志 民族政治意识，培养对国家 “有用的、驯服的臣民”。

1871 年 4 月颁布的《德意志帝国宪法》，对第二帝 国的国家性质和基本制度做了详细规定。随着宪法在国 家治理中作用的增强, 宪法教育开始萌芽, 并逐步融入 国民教育中。一些公立学校开始要求中学毕业生必须能 对宪法和国家政治体系进行描述。1890 年召开的 “帝国 学校工作会议”, 决定在高级中学历史课中补充有关宪 法、行政、社会经济政策等内容。1911 年普鲁士文化部 决定在高级中学实施 “公民学” 课程, 突出宪法地位, 内容包括国家、国会、自我管理机构、行政当局及其职 务范围、社会政策以及妇女的经济和法律地位。

1919 年德意志第一帝国垮台, 魏玛共和国建立, 德 国历史上第一部资产阶级民主宪法《魏玛宪法》将政治 教育作为一项基本国策, 要求 “各学校应致力于道德教 化, 国民节操, 使人民在德意志民族精神上及国际协和 上, 能造就人格及发展职业才能。”。在义务教育阶段, 政治教育是学校教育的重要组成部分, 宪法规定 “国民 常识及劳动课程为学校科目之一。学生于其就学义务完 毕时, 各得宪法印本一册。”, 以凸显宪法教育的重要 地位。1924 年成立的 “国民教育委员会” , 在《魏玛宪 法》有关学校政治教育精神的指导下, 制定了政治教育 课程组织原则, 包括 “一般原则” 和 “特殊原则”。 “一般原则” 规定了公民课程的任务和目标：促进公民 对宪法赋予的权利和义务的理解, 并培育他们正确的义 务观。“特殊原则” 对公立学校规定：公民课程要从公 共课如经济学、社会学、管理学、法学及宪法中提取素 材; 从中年级起，所有课目都要服务于公民教育，要启 发少儿对国家和民族的感知, 在中学最后三个年级, 要 特别安排有关国家本质、结构及含义的课程。这样在义 务教育阶段形成了一套较完整的政治教育制度和实施 细则。

1933 年德意志第三帝国建立后, 希特勒及其纳粹党 徒在政党、议会、政府、司法及社会生活各个领域推行 纳粹 “一体化” ，通过非法手段要求国会通过了 “授权 法”，在事实上废止了魏玛时期的宪法, 政治教育开始 沦为传播纳粹主义、维护法西斯独裁的工具。在反理性 主义、极端种族主义、军国主义等思想的主导下, 纳粹 通过政治教化手段传播其反动政治文化, 成为德国政治 教育史上的一个污点。

1949 年颁布的《德意志联邦共和国基本法》, 继承 了《魏玛宪法》的部分原则和内容。随后建立的联邦德 国以之为价值基础、指导原则、核心内容, 对民众开展 了持续、系统的政治教育。其实质是在对纳粹德国服务 于 “侵略扩张和种族纯洁” 的反动政治教化批判反思,
和对魏玛共和国 “基于国家和民族”的政治教育扬弃 基础上的资产阶级民主教育。以《基本法》为核心的政 治教育对于在德国民众中传播资本主义价值理念、推动 德国社会政治文化转型、促进德国资产阶级民主政治发 展做出了重要贡献。

\section{3. 宪法爱国主义是当代德国政治教育的基础 理论}

“宪法爱国主义”（Verfassungspatriotismus）, 是战后德国学者反思纳粹主义、破解旧的德意志民族国 家认同模式，试图建构一种新的基于宪法的公民认同模 式而提出的理论。它区别于民族主义和世界主义，也不 同于宽泛的共和爱国主义，主要回答了关于集体自我认 知的问题、关于成员资格的问题、关于公民的权利与义 务以及成为公民的标准问题，是战后德国资产阶级民主 政治教育的基础理论。

\section{1. 战后初期宪法爱国主义的思想奠基}

战后初期，雅斯贝尔斯在《罪责问题: 关于德国的 政治责任》（1946）中提出的 “集体罪责” 问题，对宪 法爱国主义的概念提出和理论建构起到了关键性理论 一实践导向作用。雅斯贝尔斯否定其老师马克斯 - 韦伯 关于 “自由主义政治认同和民族国家政治框架可以共 同为德意志民族造福” 的观点, 主张通过某种特别的国 民认同，或道德上的集体认同来保障政治稳定。他敦促 每个德国人深刻反省、承担起作为共同体成员的共同责 任，从而为德国实现政治新生奠定坚实的政治一道德基 础。因而提出了德意志民族的 “集体罪责” 说，即 “一 个民主的政治认同以及真正的 “社会整合” 只有通过 德国人承担集体责任方能获得。”至于如何让民众承担 集体责任，他认为一种共同的政治价值存在是必须的， 而《基本法》的颁布正提供了这样的价值基础。扬一维 尔纳 - 米勒指出, 雅斯贝尔斯的 “集体罪责” 思想，对 后来哈贝马斯的 “宪法爱国主义构想” 意义重大， “正 是从德国的罪责精神中孕育和诞生了宪法爱国主义”。

法学理论家鲁道夫・斯门德 (Rudolf Smend) 是战 后新型民主宪法的坚定支持者。他的“整合理论” 指出 要给予国民共同的政治价值或原则, 主张通过公民投票 实现民主整合，类似国歌、国旗的所谓 “民主象征” 作 用重大，而最为关键的是存在于政治体系中的普遍信任 与自豪感。斯门徳及其追随者将宪法置于政治秩序的中 心, 认为宪法内含了源自特定国家的政治文化和传统的 一套价值秩序。在 “整合理论” 影响下, 宪法在战后德 国政治思想领域占据了重要地位并得到了广泛传播，宪 法法院也成为德国最受尊重的公共机构之一。 


\section{2. 宪法爱国主义概念的提出与理论建构}

作为战后德国政治思想主要创建者之一的多尔 夫・施特恩贝格尔 (Dolf Sternberger), 承续并推进 了雅斯贝尔斯对德意志传统政治思想的反思。在 1979 年, 为纪念 《基本法》诞生 30 周年，施特恩贝格尔在 《法兰克福汇报》首次提出了宪法爱国主义的概念。面 对德意志民族被分裂为两个政权的现实，他提出 “公民 的国家认同应建立在对宪法价值与制度的信任上，而非 完全依赖那种语言、血缘与文化的一致性”。施特恩贝 格尔倡导依靠 “宪法之友” 来保护政治体制, 也就是所 谓 “保卫型宪法爱国主义”，其主要目的是保障政治稳 定。这种 “保卫型宪法爱国主义” 需要较低的政治容忍 度以及较强的教育元素, 通过《基本法》教育达到爱国 目的。

哈贝马斯在施特恩贝格尔的基础上，将宪法爱国主 义概括为对一套政治原则的有意识的认定，并认为德国 不可能再回到以 “公民友谊”、“民族伙伴” 为中心的前 民族爱国主义时代, 取而代之的是以劳伦斯 - 科尔伯格 的心理学模型为基础的 “后传统认同”, 即注重权利和 民主程序而非历史认同。与施特恩贝格尔不同, “哈贝 马斯更加关注公共领域, 主张为公民提供一个公理性空 间, 强调传统上关于国家的参考点（领土、组织机构、 司法暴力）将要被一个强调开放性的沟通过程所取代, 而这一开放性的沟通过程需要宪法所保护的权利给予 形式上的支持。” 有人将其主张称为“净化式爱国主义”, 是一种政治忠诚形式。一言蔽之, 哈贝马斯的宪法爱国 主义的核心是将政治忠诚贯穿一整套自由民主宪政的 规范、价值以及程序之中, 宪法爱国主义原则需要嵌入 到具体的制度和实践中, 其结果将会使民众之间存在由 宪法所形成的凝聚力。

\section{3. 政治教育学者对宪法爱国主义思想的吸 收}

战后德国政治教育理论大致可分为传统保守主义 流派、新保守主义流派以及激进主义流派。虽然各流派 的思想风格和理论特质不尽相同，但都认同通过政治教 育来实施所谓的 “宪法保护” (Verfassungsschutz), 认为相比国家暴力机器, 政治教育是最为长远、有效的 保护宪法的方式。以李特 (Theodor Litt) 为代表的传 统保守主义流派极力主张维系 “权威型政治文化” ，培 养忠于德国政治体制的 “国家公民”，维护新生的、还 未得到民众普遍拥护的宪法秩序; 新保守主义流派代表 人物苏特 (Bernhard Sutor) 认为《基本法》是德国政 治教育的源泉，并在其著作《基本法与政治教育》中， 系统阐述了两者的关系。他提出应把民众对宪法知识和 宪法价值的普遍接受作为政治教育的最高目标，在此基 础上，按照 “理性政治人” 的模式培养人对政治的理性 精神; 偏激进主义的基泽克（Hermann Giesecke）将《基 本法》看作 “长期的历史解放和民主化进程” , 认为公
民宪法意识的培养过程是公民自我解放的过程，政治教 育应培养基于宪法的成熟公民。

虽然战后德国各政治教育流派依据的基本理论及 采取的方式各异，但都力图建构一种解释系统，以说明 和论证建立在《基本法》基础上的政治体系和政治权力 对于战后德国建立资本主义民主文化的重要性与合法 性; 都深刻分析了德国 “宪法保护” 工作面临的挑战和 议会民主体制面临的危机，特别是政治文化危机，并阐 述了危机产生的原因和破解危机的基本思路; 都意在完 善资产阶级民主体制下的政治教育体系，丰富政治教育 的目标、价值取向、内容和方式方法。

\section{4. 宪法是当代德国政治教育的核心内容}

德国统治集团通过政治教育途径，在当代德国社会 建设、发展起与宪法精神相一致的资本主义民主政治文 化。在长期的实践中，逐步构建了 “联邦议会进行总决 策和总监督、联邦政府进行组织和管理、学校主导实施、 政党协助实施、社会组织参与实施的政治教育实践体 系, 其中每个环节又都以宪法为指导原则和评价标准, 以培养民众的宪法意识为核心。

\section{1. 以宪法为根本依据确立政治教育目标}

建国之初，德国民众经历了从纳粹时期的 “政治狂 热” 到战争惨败后的 “政治冷漠”, 巨大的心理落差使 他们对新生的、依附于西方盟国的联邦共和国普遍缺乏 认同感，对《基本法》所设计的资本主义民主政治制度、 道路缺乏信心。为此, 联邦议会开展了以确立民众的政 治主体意识、提高政治合作意识为目标的政治教育, 促 进民众对宪法框架下的德国资本主义社会政治经济体 制的 “集体认同”，根本目的是夯实资产阶级统治的 “合 法性”。

20 世纪 60、70 年代, 在经历了大学生反叛运动对 资本主义制度的批判, 以及与之相伴的激进抗议运动 后, 联邦议会对政治教育的目标进行了 “再定位”, 即 引导民众合法、有序、理性地参与国家政治生活。以此 为原则，专司政治教育工作的联邦内政部下属机构 “联 邦政治教育中心”, 将其工作目标确立为: “引导公民赞 同《基本法》规定的社会法制国家的自由民主秩序; 确 资产阶级民主的基本内涵是依据《基本法》规定的民主 政治秩序构建资产阶级民主政治文化。”

20 世纪末，面对错综复杂的国际国内政治环境，联 邦议会规定政治教育要通过传授《基本法》规定的民主 意识以及参与政治生活所需的知识和能力, 达到弘扬宪 法精神、培养民众批判能力及将民主作为一种生活方式 的目标。1991 年联邦政府提交议会的一份报告中提出,

“民主国家要以公民的责任和能力为导向，如果人们没 有能力和意愿来充实自身的生活, 那么最自由的宪法也 只是一个形式而已。” 政治教育主管部门、专家学者都 认定，《基本法》及其规定的民主程序仅仅作为一种价 
值规定是不够的, 只有为大众所接受并运用于实践, 才 能转化为大众政治认同的价值基础。联邦政府规定：所 有学生到了一定阶段, 必须认真研读当代德国及各个历 史时期的宪法, 了解宪法的内容体系、基本精神、价值 取向等, 以此加深对当今宪法的认知, 树立宪法至上意 识。

\section{2. 以宪法为核心内容开展学校政治教育}

学校是德国政治教育的主场地, 课堂教学是学校政 治教育的主要方式。德国在教育体制上实行的是联邦 制, 各州在政治教育领域享有较大的自主权, 但都以不 脱离《基本法》的基本框架为前提。学校政治教育的根 本目标和任务是通过系统的课程教学, 使学生掌握宪法 基本内容, 拥护宪法制度, 认同资产阶级民主价值, 为 日后参与社会政治生活奠定知识与能力基础。

在教材方面, 不涉及宪法内容的教科书是禁止使用 的。如在黑森州的高中政治课教材中, 低年级的教学内 容包括《基本法》规定的公民基本权利和义务, 主权在 民、权力分立、民主社会与法治国家的内涵; 高年级的 教学内容则涉及政治的结构与过程, 宪法规定与宪法现 实, 其中有基本权利的权衡及宪法与联邦宪法法院的介 绍以及权力交叠, 同时还涉及欧洲宪法的讨论, 现代宪 法国家的理论基础等。另外, 黑森州设有专门的宪法教 育课程, 涉及到欧盟宪法以及宪法国家的理论, 探讨范 围从德国宪法到欧盟及宪法理论层面。在拜仁州, 高中 政治课主要内容由 “国家体制”、“宪法与民主政治理 论”、“国家与公民”、“国际政治与国际关系”、“经济 制度与经济成就” 五部分构成, 其中国家体制、宪法与 民主政治理论是核心, 该部分以《基本法》为依据, 集 中回答德国宪政的历史和当代政治体系的基础、结构、 功能和价值, 以促使学生认识、理解、认同德国政治体 系。

此外, 宪法教育理念还贯穿在政治教育课程的具体 教学中。如汉堡州文理中学高年级《政治/社会/经济课 程教学大纲》就规定了该课程的任务、目标、内容、教 学原则与方法, 指出教学目标是促进学生的所谓 “民主 能力” 的养成与增强; 要求学生能自主确定自身的利益、 权利与义务, 并承担社会责任; 能认识到在一个民主多 元的社会中利益冲突存在的必然性, 但应当在遵守宪法 基本价值的前提下, 通过合于宪法的形式予以解决。课 堂教学多采用教师讲授和师生讨论的方法, 促使宪法精 神逐步融入学生生活实践。

\section{3. 以宪法为基本原则遴选政治教育社会承 担者}

除系统的学校教育外, 政党及社会政治教育同样也 以宪法作为教育实践和教育管理的基本遵循。联邦议会 对 “联邦政治教育中心” 进行监督的一个基本原则和标 准, 就是其开展的政治教育工作所体现的政治立场是否
符合《基本法》的精神和要求，与此同时，“联邦政治 教育中心” 又以《基本法》的精神和要求, 遴选、资助 社会机构承担政治教育工作。20 世纪 80 年代至今, “联 邦政治教育中心” 逐步加大对社会力量参与政治教育工 作的支持力度，以加强社会政治教育资源体系建设。这 些政治教育的社会机构会受到严格的政治审查，只有拥 护并贯彻宪法体现的价值、原则，并保证根据宪法目标 开展工作的，才可以被授以 “受认证的承担者”之名， 获得开展政治教育活动的经费资助。

政党在德国政治教育体系中处于特殊地位。根据 《基本法》, 政党应当协力形成人民的政治意愿。德国 《政党法》规定, “政党必须在公共生活所有方面参与 形成人民政治意愿, 特别是对形成公共意见施加影响, 激发并加强政治教育, 促进积极的对政治生活的公开参 加, 培养有能力的人承担公共责任。”德国各大政党都建 有附属的政治基金会，联邦议会通过财政拨款资助这些 基金会开展对民众的政党宣传及政治教育工作，并要求 它们开展的宣传教育工作必须以维护宪法为宗旨、保证 与国家的意识形态和政治教育原则方针相一致。还特别 强调坚决打击任何试图盅惑人们违反宪法的活动。

\section{5. 评价与启示}

通过上述对德国宪法教育的历史沿革、思想理论、 实践工作的梳理, 能够帮助我们进一步揭示和把握西方 政治教育所体现出的阶级性和意识形态特征。标榜所谓 “价值中立”、“超党性”、“无差别对待”, 是西方国家 政治教育乃至整个意识形态工作的重要特征。但透过当 代德国宪法教育的具体表现来看，其政治教育实际上有 十分明确的价值取向, 那就是作为西方资产阶级核心价 值观的民主、分权、自由等。以宪法教育为核心的德国 政治教育，其实质脱离不了 “阶级的教育”，在本质上 是获取民众对资产阶级统治的认同，维护资本主义宪政 体系。对此, 要始终保持清醒的头脑, 不断提升我们思 想政治教育及意识形态工作的自觉性。当然, 在党中央 依宪治国理念的提出和深入贯彻的背景下, 也应不断加 强和改进新时代我国宪法教育。德国宪法教育的经验有 一定启示意义:

\section{1. 高度重视宪法教育}

宪法是一个国家或民族为自身前途命运所做的制 度安排, 在一国法律体系中具有最高的法律地位和法律 效力。宪法的权威源自全体人民的真心拥护和坚定信 仰, 这又以系统持续、广泛深入的宪法教育为重要基础。 习近平总书记指出, “要加强宪法学习宣传教育, 弘扬 宪法精神、普及宪法知识……, 要坚持从青少年抓起, 把宪法法律教育纳入国民教育体系，引导青少年从小掌 握宪法法律知识、树立宪法法律意识、养成遵法守法习 惯。”宪法教育是深化尊崇宪法意识不可或缺的力量, 应贯穿于思想政治教育始终，贯穿每个社会成员的成长 
和发展始终。要在全社会形成尊崇宪法意识, 为推进全 面依法治国战略的实施提供思想保障。教育主管部门要 高度重视宪法教育, 提升宪法教育在国民教育体系中的 地位, 增加宪法教育在思想政治教育内容中的比重, 从 实现中华民族伟大复兴梦的战略高度对宪法教育进行 顶层规划, 从立法的高度保障宪法教育的有效实施。

\section{2. 加强学校宪法教育教学}

学校是青少年完成政治社会化的主要机构, 系统的 课程教学是学校宪法教育的主要途径。加强我国学校宪 法教育教学, 一是要遵循青少年不同年龄阶段认知特 点、思想品德形成发展规律和政治社会化规律, 专门针 对小学、中学、大学不同阶段学生制订宪法教育内容和 教学方案, 注重小学《道德与法制》、中学《思想政治》、 大学《思想道德修养与法律基础》等课程教学内容的衔 接与递进关系, 帮助青少年学生深刻领会我国宪法发展 的历史逻辑、政治逻辑、法理逻辑; 二是在宪法教育中 贯彻 “课程思政” 理念, 充分发挥不同课程、不同学科 的德育功能, 在中小学语文、历史、地理等课程及高校 人文社会学科专业课中探索、挖掘宪法教育的知识点和 切入点, 做到多课程、多专业、多学科同频共振、同向 而行、协同推进; 三是把宪法教育贯穿每个育人环节, 要在课程、科研、实践、文化、网络、心理、管理、服 务、资助、组织等方面中体现宪法的精神价值导向, 让 尊崇宪法、学习宪法、遵守宪法、维护宪法、运用宪法 成为广大师生的自觉行动。

\section{3. 形成社会宪法教育合力}

思想政治教育 “以合力为上, 以分散甚至抵触为 害”。加强我国社会宪法教育, 也要积极调动社会各方 面力量形成教育 “合力”, “要在全社会广泛开展尊崇宪 法、学习宪法、遵守宪法、维护宪法、运用宪法的宣传 教育，弘扬宪法精神，弘扬社会主义法治意识，增强广 大干部群众的宪法意识, 使全体人民成为宪法的忠实崇 尚者、自觉遵守者、坚定捍卫者。”党和政府应该充分 发挥在宪法教育中的主导作用, 调动、整合社会宪法教 育资源, 拓展宪法教育渠道, 积极支持城乡基层自治组 织、社会团体、人民团体、行业组织等社会力量参与其 中, 以提升宪法教育的社会化程度。做到学习宣传宪法 知识全员覆盖, 培育尊崇宪法意识, 弘扬依宪治国精神, 在全社会营造良好的宪法实施氛围, 使全体社会成员在 生活中尊法、学法、守法、用法, 树立宪法至上观念, 促进中国特色社会主义宪法文化繁荣发展。

\section{REFERENCES}

[1] Jin Shoutie, Guilty introspection: overcoming the new life of the past, Social, J. Sciences in China. 2015 (09): 26-42+203-204
[2] Jan-Werner Müller, On the Origins of Constitu-tional Patriotism, Contemporary Political Theory, 2006, (5).

[3] Tong Fei, An Analysis of the Goal, Attributes and Performance of Germany Political Education, J. Theory Monthly, 2008, (4).

[4] Ruan Yifan, Peng Tao, A Historical Survey of the Germany "Federal Center for Political Education",J.Wuhan University Journal(Humanity Sciences),2010,(3).

[5] Chen Yanhui, A Comparative Study on the Outline of Political Education in Hessen Middle School in Germany, J. Monograph, 2013, (26).

[6] Xi Jinping, Pay more attention to the important role of the constitution and raise the implementation of the constitution to a new level, J. Party building. 2018, (3). Reference to a book:

[7] Fu Anzhou, Ruan Yifan, Peng Tao, German Political Education Studies, People's Publishing House,. Beijing, 2010 .

[8] Karl Jaspers, Die Schuldfrage: Ein Beitrag zur de-utschen Frage, Zurich: Artemis.1946:10-14.

[9] Jan-Werner Miller. Constitutional patriotism. Deng Xiaojing, translator. The Commercial Press, Beijing, 2012.

[10] Jan-Werner Müller, On the Origins of Constitu-tional Patriotism, Contemporary Political Theory, 2006, (5).

[11] Rudolf Smend, "Verfassung und Verfassungsfre-cht [1928]," in Staatsrechtliche Abhandlungen und andere Aufsatze, Berlin: Duncker and Humblot, 1994.

[12] $\mathrm{Xu}$ Jie. A study on the Theory of Habermas Constitution patriotism, Nanjing University of Science and Technology, Nanjing, 2013.

[13] Dolf Sternberger, Staatsfreundschaft [Schriften -IV] Frankfurt/Main:Suhrkamp,1980.

[14] Hans-Werner Kuhn, Politische Bildung in Deutschland: Entwicklung-Stand-Perspektiven, Op-laden, 1993.

[15] Petrik, A.,Otto, H.. Wacker,U.. et. al. (Hrsg.) Bildungsplan gymnasiale Oberstufe, Politik/Gesell-schaft/Wirtschaft [M].Hamburg: Freie und Hansestadt Hamburg Behörde für Schule und Berufsbildung.2009. 
[16]

Information

on

https://baike.baidu.com/item/\%E9\%AD\%8F\%E7\%8E\%

9B\%E5\%AE\%AA\%E6\%B3\%95/8516506?fr=aladdin. 